\title{
VARIATIONS IN NUMBER OF DOPAMINE NEURONS AND TYROSINE HYDROXYLASE ACTIVITY IN HYPOTHALAMUS OF TWO MOUSE STRAINS ${ }^{1}$
}

\author{
HARRIET BAKER, ${ }^{2}$ TONG H. JOH, DAVID A. RUGGIERO, AND DONALD J. REIS \\ Laboratory of Neurobiology, Cornell University Medical College, New York, New York 10021 \\ Received May 3, 1982; Revised August 23, 1982; Accepted October 8, 1982
}

\begin{abstract}
Mice of the BALB/cJ strain have more neurons and greater tyrosine hydroxylase (TH) activity in the midbrain than mice of the CBA/J strain (Baker, H., T. H. Joh, and D. J. Reis (1980) Proc. Natl. Acad. Sci. U. S. A. 77: 4369-4373). To determine whether the strain differences in dopamine (DA) neuron number and regional TH activity are more generalized, regional TH activity was measured and counts of neurons containing the enzyme were made in the hypothalamus of male mice of the BALB/cJ and CBA/J strains. TH activity was measured in dissections of whole hypothalamus (excluding the preoptic area), the preoptic area containing a rostral extension of the A14 group, the mediobasal hypothalamus containing the A12 group, and the mediodorsal hypothalamus containing neurons of the A13 and A14 groups. Serial sections were taken and the number of DA neurons was established by counting at 50 - to $60-\mu \mathrm{m}$ intervals all cells stained for TH through each area. In conjunction with data obtained biochemically, the average amount of TH per neuron was determined. In all areas, TH activity in CBA/J mice was significantly less $(p<0.001)$ than in $\mathrm{BALB} / \mathrm{cJ}$ mice, ranging from $48 \%$ in the mediobasal hypothalamus to $71 \%$ in the medial and dorsal hypothalamus. The number of TH-containing neurons was also significantly less in the $\mathrm{CBA} / \mathrm{J}$ strain $(p<0.001)$, ranging from $49 \%$ in the preoptic area to $74 \%$ in the mediobasal hypothalamus (MBH). With the exception of the MBH, enzyme activity per neuron was similar in both strains. In the $\mathrm{MBH}$, strain differences in TH activity were greater than those for neuron number, resulting in less TH activity per neuron in the CBA/J strain.

The results suggest that strain differences in the number of DA neurons are widespread and involve DA systems throughout the brain. Therefore, differences in whole brain TH activity cannot be attributed only to differences in specific regions. Our findings further support the view that the number of neurons of a specific chemical class may be under genetic control.
\end{abstract}

Studies from this laboratory (Ross et al., 1976; Baker et al., 1980b; Reis et al., 1982) have established that the activity and amount of the catecholamine biosynthetic enzyme, tyrosine hydroxylase (TH), vary in the midbrain of two inbred strains of mice, CBA/J and BALB/cJ. By regional dissection, we determined that in $\mathrm{CBA} / \mathrm{J}$ mice, TH activity is 60 to $80 \%$ of that of the BALB/cJ mice in regions of midbrain containing cell bodies of dopamine (DA) neurons of either the A9 (nigrostriatal) or A10 (mesolimbic/mesocortical) groups. Differences in enzyme activity in the cell bodies are also reflected in their terminal fields: TH activity is substantially greater in the corpus striatum (the target of the A9 neurons) and the

\footnotetext{
${ }^{1}$ This work was supported by National Institute of Mental Health Grant MH 33190 and National Heart, Lung, and Blood Institute Grant HL 18974. A preliminary report of this study has been made (Baker, H., T. H. Joh, and D. J. Reis (1980) Soc. Neurosci. Abstr. 6: 742).

${ }^{2}$ To whom correspondence should be addressed.
}

olfactory tubercle, nucleus accumbens, and frontal cortex (targets of the A10 group) (Reis et al., 1982). By staining the midbrains with antibodies to TH and by careful morphometric analysis, we found that differences in $\mathrm{TH}$ activity are entirely accounted for by variations in the number of neurons containing the enzyme (Baker et al., 1980b).

These observations raise the interesting questions: are differences in the number of DA neurons restricted only to midbrain DA systems or are they shared by other DA networks in the brain? In other words, are the variations regional and do they reflect differences in organization of the midbrain, or are they variations in a chemically defined system of neurons more widely dispersed throughout the central nervous system?

To answer these questions, we undertook the present study of hypothalamic DA systems in the two mouse strains. The hypothalamus contains several well defined and anatomically segregated groups of DA neurons 
(Moore and Bloom, 1978). These include the A12 group in the arcuate nucleus, the A13 group in the zona incerta, and the A14 group lying periventricularly. In the present study, we sought, first, by regional dissection, to determine whether TH activity in hypothalamus, as in midbrain, is greater in BALB/cJ than in CBA/ J mice and, second, by counting the number of neurons stained with antibodies to $\mathrm{TH}$, to assess whether such variations, if present, can be attributed to differences in the number of neurons containing the enzyme. We shall demonstrate that BALB/cJ mice have greater TH activity in all hypothalamic neuronal groups and that the difference appears to be almost entirely attributable to variations in the number of neurons containing the enzyme.

\section{Materials and Methods}

Animals. Six-week-old BAIR/cJ and CRA/J male mice were obtained from the Jackson Laboratory, Bar Harbor, ME. Upon arrival, they were placed, five in a cage, in a thermostatically controlled $\left(22^{\circ} \mathrm{C}\right)$ room on a 12-hr light/dark cycle (0700 to 1900$)$, with laboratory chow and water ad libilum. They were adapted to the environment for 2 weeks before sacrifice.

Biochemical assays and brain dissections. For biochemical analysis, mice were stunned and decapitated. Brains were removed and immediately placed on ice. Two types of dissection were performed. In the first, the whole hypothalamus (Figs. 1 and 2), excluding the preoptic and mammillary regions, was removed en bloc by sharp dissection from a ventral approach. The boundaries of the block were: rostral, just posterior to the optic chiasm; lateral, the choroidal fissures; and caudal, the rostral pole of the mammillary bodies. The tissue was removed by a horizontal cut $2 \mathrm{~mm}$ from the ventral surface of the brain. The preoptic region was not included in this dissection.

In the second dissection, the preoptic region and mediobasal hypothalamus were removed separately from the remainder of the hypothalamus. The preoptic region (Figs. 1 and 3) was removed through a ventral approach with a cut just posterior to the optic chiasm as the caudal border, the olfactory tubercles as the lateral and rostral borders, and the anterior commissure as the dorsal border. Care was taken not to include any part of the olfactory tubcrcles in the dissection. The mediobasal hypothalamus, containing the arcuate nucleus and its A12 dopaminergic group, was removed under a dissecting microscope and consisted of an area lying $2 \mathrm{~mm}$ rostral to, $1 \mathrm{~mm}$ to either side of, and $1 \mathrm{~mm}$ dorsal to the median eminence, with the mammillary bodies as the posterior border (Figs. 1 and 2). The remainder of the hypothalamus, containing the dopamine neurons of the periventricular group (caudal A14) and the zona incerta (A13), was then dissected out, as described above.

Tissue was immediately frozen on dry ice and homogenized in at least $10 \mathrm{vol}$ of a $5 \mathrm{~mm}$ potassium phosphate buffer, $\mathrm{pH} 7$, containing $0.2 \%$ Triton $\mathrm{X}-100$. TH was assayed by the method of Reis et al. (1975). The final concentration of tyrosine in the reaction mixture was 0.2 $\mathrm{mM}$. Dopamine $\beta$-hydroxylase (DBH) activity was measured by modification of the method of Reis and Molinoff (1972).
Immunohistochemistry. For immunohistochemical localization of tyrosine hydroxylase, mice were anesthetized with $0.1 \mathrm{ml}$ of Nembutal $(50 \mathrm{mg} / \mathrm{ml}$, i.p.; Abbott Laboratories, Chicago, IL) and perfused transcardially with a $4 \%$ paraformaldehyde solution in $0.1 \mathrm{M}$ phosphate buffer. Brains were postfixed in the cold for $1 \mathrm{hr}$ in fixative and washed for several hours with buffer. The brains were then infiltratd with a $30 \%$ sucrose solution (overnight) and frozen over dry ice, and $14-\mu \mathrm{m}$ serial sections were taken through the preoptic area and hypothalamus. One of every three sections was stained with antibody to $\mathrm{TH}$, as previously described (Baker et al.,

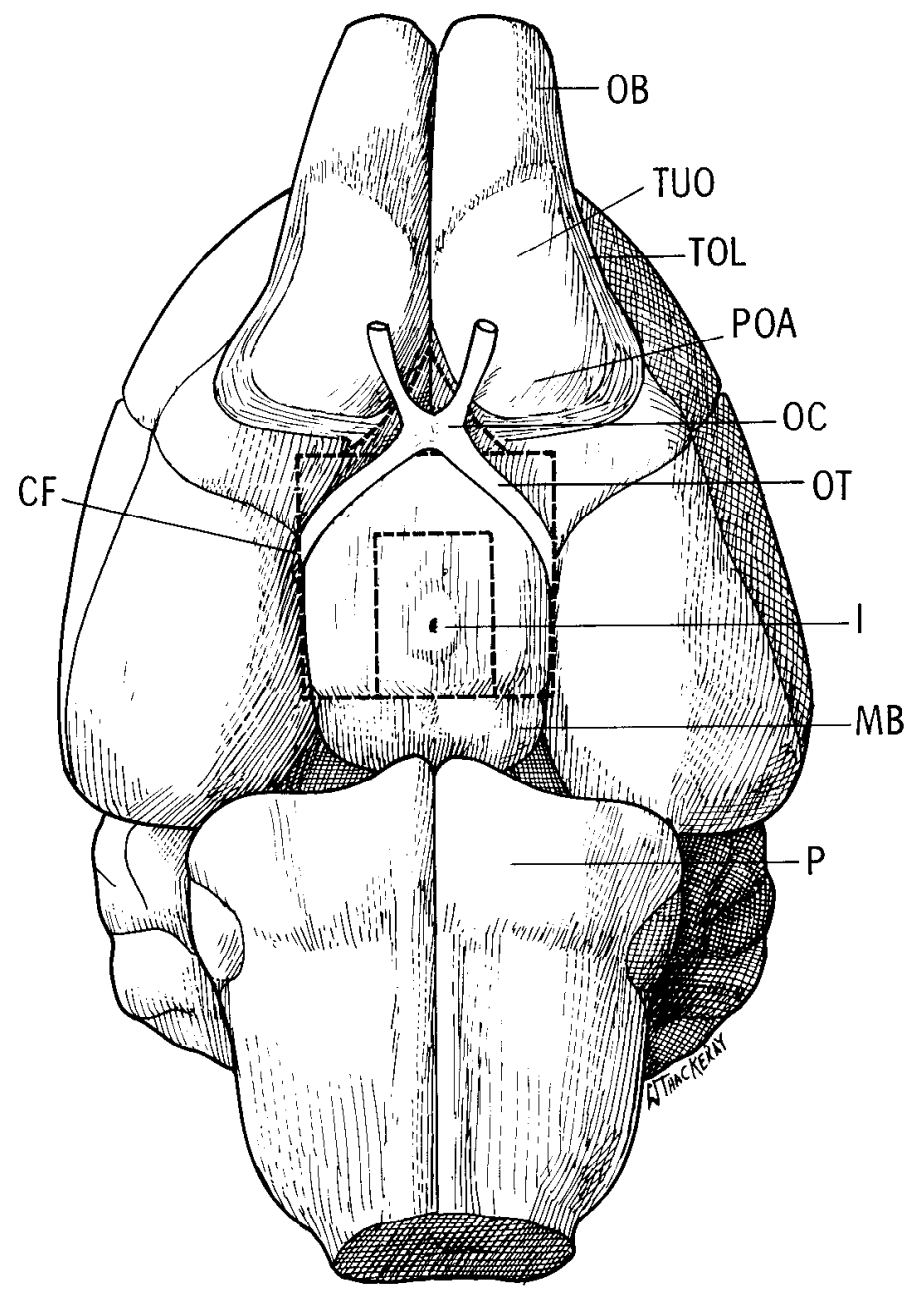

Figure 1. Schematic representation of the ventral surface of the mouse brain. For measurement of TH activity, hypothalamic and preoptic nuclei were removed from the brain, using a ventral approach. The preoptic region was removed first by sharp dissection, using the boundaries indicated by the triangle. The dorsal boundary of the dissection is indicated in Figure 3. The hypothalamus dissection includes the area indicated by the large rectangle. The dorsal extent of the dissection is indicated in Figure 2. In some experiments, the mediobasal hypothalamus was removed first as indicated by the small rectangle and, sccond, the remaining hypothalamus was removed using the dissection indicated by the large rectangle. Again, the dorsal and lateral extent of the tissue block is illustrated in Figure 2. $C F$, choroidal fissure; $I$, infundibulum; $M B$, mammillary body; $O B$, olfactory bulb; $O C$, optic chiasm; $O T$, optic tract; $P$, pons; $P O A$, preoptic area; $T O L$, lateral olfactory tract; $T U O$, olfactory tubercle. 


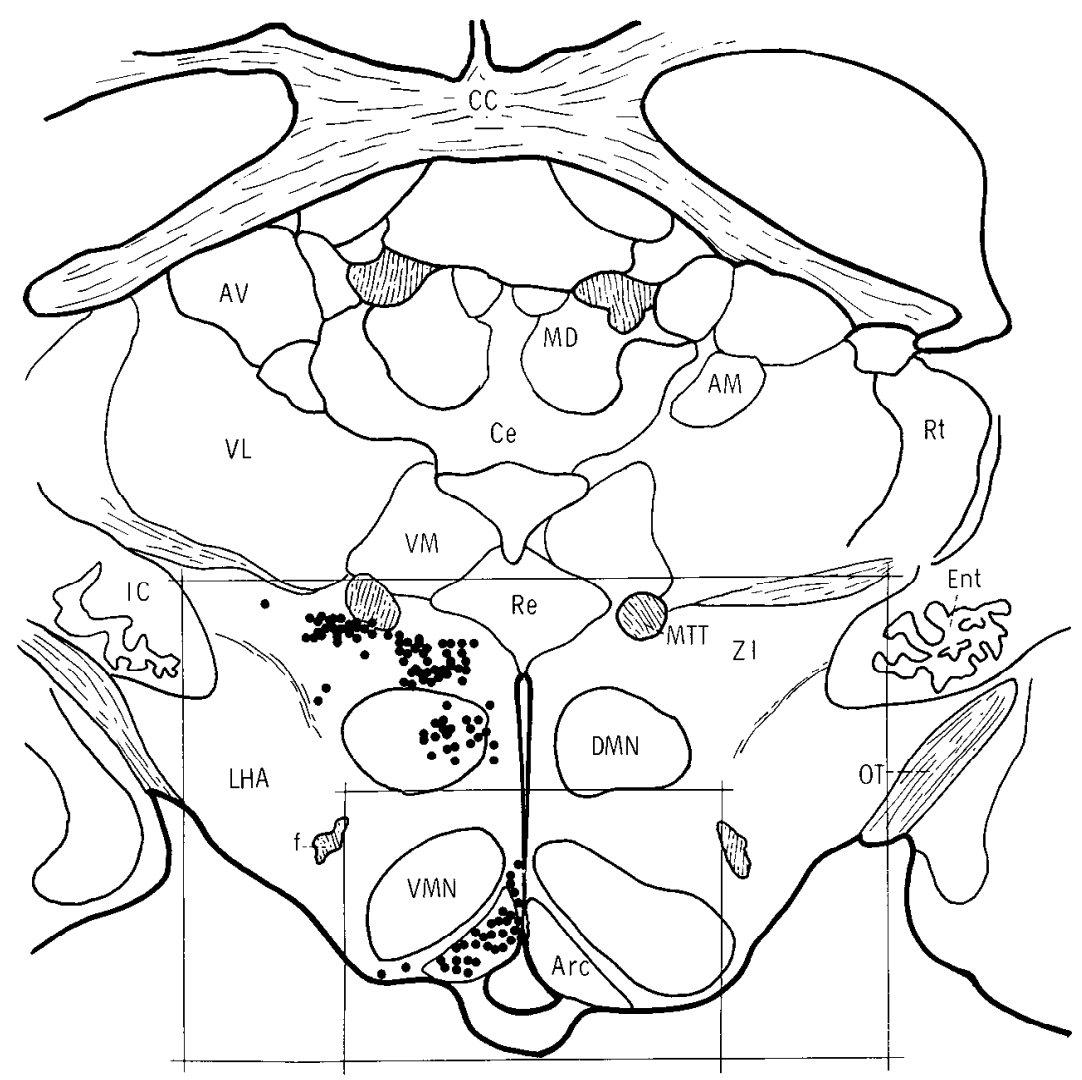

Figure 2. Diagrammatic representation of TH-containing neurons in the midtuberal region of the hypothalamus of the BALB/ $\mathrm{cJ}$ mouse strain. Neurons are indicated by the solid circles. Neurons were in a similar position in CBA/J mice. The larger rectangle indicates the area included in the whole hypothalamic dissections for determination of $\mathrm{TH}$ activity. For regional dissections, the area in the smaller rectangle (mediobasal hypothalamus) was removed first, and the rest of the hypothalamus (the middle and dorsal regions) was dissected using the area indicated by the larger rectangle. AM, anteromedial thalamic nucleus; $A r c$, arcuatc nucleus; $A V$, anteroventral thalamic nuclcus; $C C$, corpus callosum; $C e$, central medial thalamic nucleus; $D M N$, dorsomedial hypothalamic nucleus; $E N T$, entopeduncular nucleus; $f$, fornix; $I C$, internal capsule; $L H A$, lateral hypothalamic nucleus; $M D$, medial dorsal thalamic nucleus; $M T T$, mammilothalamic tract; $O T$, optic tract; $R e$, nucleus reuniens; $R t$, reticular thalamic nucleus; $V L$, ventrolateral thalamic nucleus; $V M$, ventromedial thalamic nucleus; $V M N$, ventromedial hypothalamic nucleus; $Z I$, zona incerta.

$1980 \mathrm{~b})$. The remaining sections were stained with cresyl violet and used to determine the exact anatomical location of the presumed dopaminergic neurons stained with $\mathrm{TH}$. Antibodies to $\mathrm{TH}$ were prepared in rabbits against highly purified trypsin-treated enzyme of bovine adrenal origin, as described in detail elsewhere (Pickel et al., 1975). These antibodies reacted with equal affinity against $\mathrm{TH}$ in the brains of mice of either the BALB/cJ or $\mathrm{CBA} / \mathrm{J}$ strains, when examined by gel diffusion or immunoelectrophoresis, and equally inhibited TH activity in homogenates of brains from both strains (unpublished data).

Tissues were stained immunocytochemically by the soluble peroxidase-antiperoxidase method of Sternberger et al. (1970), as described in detail elsewhere (Teitelman et al., 1979).

Morphometry. Sections, $14 \mathrm{~m}$ thick, were taken at 50to $60-\mu \mathrm{m}$ intervals and stained for TH. Adjacent sections were stained with cresyl violet to identify specific landmarks. At $\times 25$ magnification, all TH-stained neurons were counted and related to landmarks in the hypothalamus. Neurons were examined with phase optics to emphasize the distinction between neuronal staining and background (which, with our antibody, was virtually negligible). A neuron was accepted as specifically stained when the reaction product was restricted to the cytoplasm, with an intensity perceptibly greater than background. All stained neurons were counted regardless of the normal variations in staining intensity (Benno et al., 1982).

For each animal, the number of neurons along the rostral-caudal axis of the brain was plotted on graph paper, with the number of neurons per section indicated on the ordinate and the distance from the most rostral extent of a specific hypothalamic group or origin on the abscissa. The area under the curve, determined by computer, represented the total number of neurons, uncorrected for double counting, in the particular brain area in an individual animal (Dornfeld et al., 1942). To obtain strain values at specific hypothalamic locations, the number of neurons, arbitrarily selected at $140-\mu \mathrm{m}$ distances from the origin, was estimated on the curve describing neuronal number in each animal. The values were averaged and variance was measured. Statistical differences of hetween-strain variations for total neuronal number for each brain area, or for the number of neurons at each 
140- $\mu \mathrm{m}$ interval through the brain areas, were established by the Student's $t$ test.

\section{Results}

Distribution of dopamine neurons in mouse hypothalamus. For purposes of orientation, it is useful to describe the distribution of TH-containing neurons in mouse hypothalamus. In general, the distribution of hypothalamic dopamine neurons in the mouse is similar to that observed in the rat (Dahlström and Fuxe, 1964; Björklund and Nobin, 1973; Hökfell et al., 1976; Moore and Bloom, 1978). The stained cells are clustered into the three major DA groups: a ventral group (comprising the A12 or arcuate area), an intermediate group (the $\mathrm{A} 14$ or periventricular area), and a dorsal group (including the A13 or incerto-hypothalamic area).

Within the ventral group (Fig. 2), the largest number of neurons is contained in the tuberal region within the arcuate nucleus (the A12 region). Some labeled cells are distributed rostrally (Fig. 3) within the ventral midline of the preoptic region, lying within the supraoptic nucleus and retrochiasmatic area.

Within the intermediate group, the DA neurons lie in three major clusters. The first cluster (the most rostral) is in the preoptic periventricular gray (Fig. 3) and extends from the decussation of the anterior commissure to the retrochiasmatic area. The second cluster originates in the midtuberal region (approximately the middle third of the hypothalamus). Within this region, periventricular neurons are contiguous with a dense clustering of labeled cells which fall within the central and peripheral subdivisions of the dorsomedial hypothalamic nucleus (Fig. 2). The third cluster (the most caudal) is in the posterior hypothalamus and includes labeled cells in the posterior hypothalamic nucleus and the bed nucleus of the supramammillary commissure.

The dorsal group consists of three major clusters of labeled cells. The most rostral cluster occupies a portion of the well defined anterior preoptic nucleus of Loo (1931), with the majority of neurons labeled at the level of the decussation of the anterior commissure (Fig. 3); the second lies within the zona incerta or A13 group (Fig. 2 ), with a smaller number of labeled neurons in the paraventricular, the dorsal, and the caudally contiguous subparafascicular hypothalamic nuclei; and a third cluster, the most caudal, lies in the caudal periventricular gray at the level of the posterior hypothalamic nucleus.

The posterior hypothalamic neurons were not included in either the biochemical or neuron number determinations; neurons of the substantia nigra and periventricular gray are also present at this level and would have contaminated the assays.

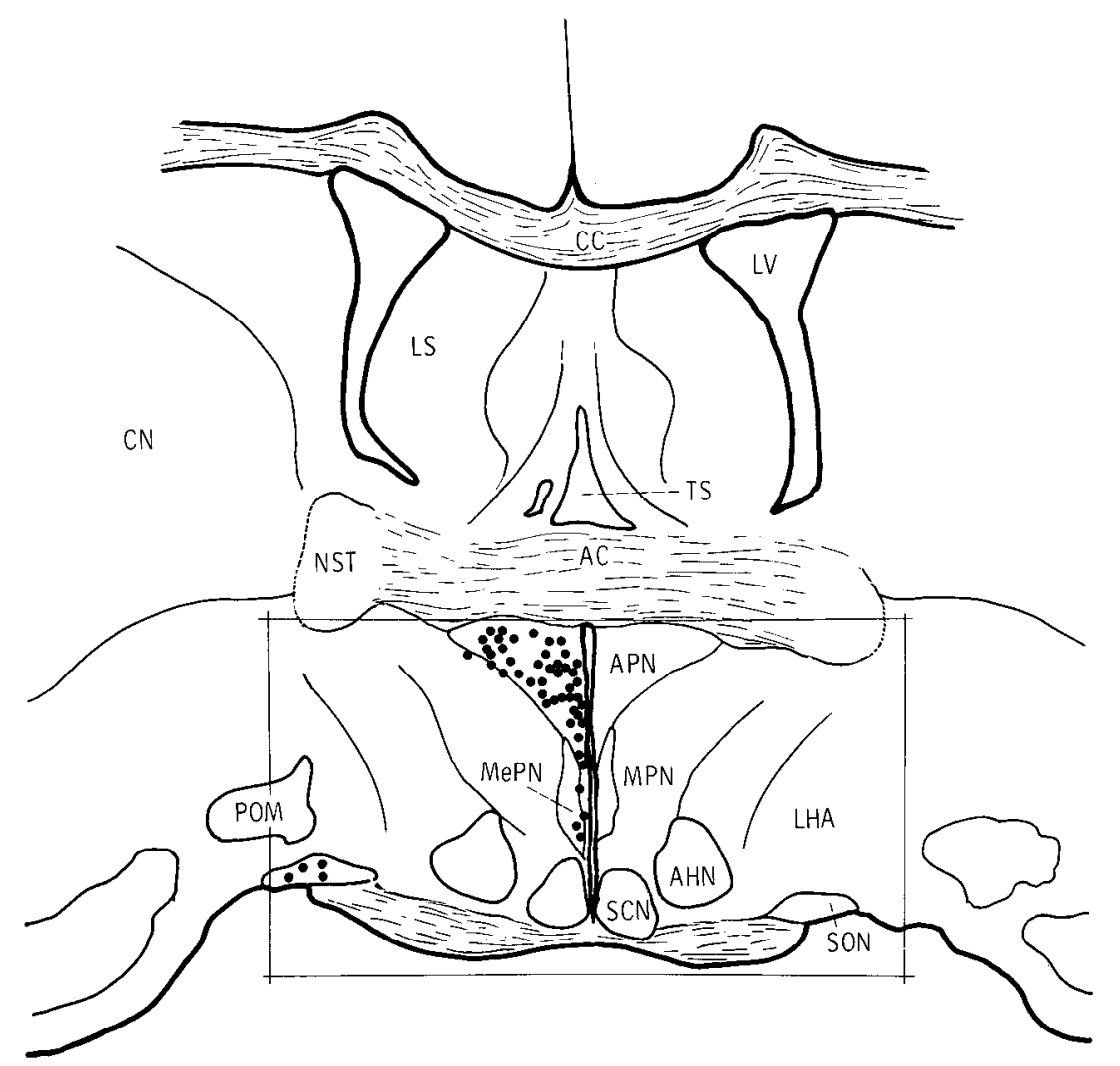

Figure 3. The location of TH-containing neurons in the mouse preoptic region. Neurons are indicated by the solid circles. The diagram is based on sections from the BALB/cJ strain, but neurons were in a similar position in CBA/J mice. The rectangle indicates the area included in the dissection of the preoptic region used for $\mathrm{TH}$ activity determinations. $A C$, anterior commissure; $A H N$, anterior hypothalamic nucleus; $A P N$, anterior preoptic nucleus; $C C$, corpus callosum; $C N$, caudate nucleus; $L H A$, lateral hypothalamic area; $L S$, lateral septum; $L V$, lateral ventricle; $M e P N$, median preoptic nucleus; $M P N$, medial preoptic nucleus; $N S T$, nucleus of the stria terminalis; $P O M$, magnocellular preoptic nucleus; $S C N$, suprachiasmatic nucleus; $S O N$, supraoptic nucleus; $T S$, nucleus triangularis septi. 
The mouse differs from the rat in the large number of TH-labeled neurons in the anterior preoptic nucleus and the dorsomedial hypothalamic nucleus. Using the same techniques, considerably fewer of these neurons were observed in the same regions in the rat (unpublished observation).

TH activity and neuron number in whole hypothalamus. TH activity was measured in a block of tissue comprising the major portion of the hypothalamus, excluding the preoptic and mammillary regions (see "Matcrials and Mcthods" for dissection procedure). This region contains cell bodies and terminals of the A12, A13, and A14 DA cell groups. TH activity in this tissue block was about $60 \%$ less in $\mathrm{CBA} / \mathrm{J}$ than in $\mathrm{BALB} / \mathrm{cJ}$ mice (Fig. 4 and Table I), whether expressed per hypothalamus or per milligram of protein.

Since, in the hypothalamus, TH enzyme is contained not only in intrinsic DA neurons and their projections, but also in the terminals of brain stem neurons synthesizing norepinephrine (NE) and epinephrine (E), it was necessary to assess whether TH activity differences were largely attributable to DA systems. Since NE and E fibers both contain the enzyme $\mathrm{DBH}$, the activity of this enzyme was measured in the same block of tissue used for the TH assay. DBH activity, in contrast to $\mathrm{TH}$ activity, was $25 \%$ less in the hypothalamus of BALB/cJ

STRAIN DIFFERENCES IN TYROSINE HYDROXYLASE AND DOPAMINE BETA HYDROXYLASE ACTIVITY IN MOUSE HYPOTHALAMUS

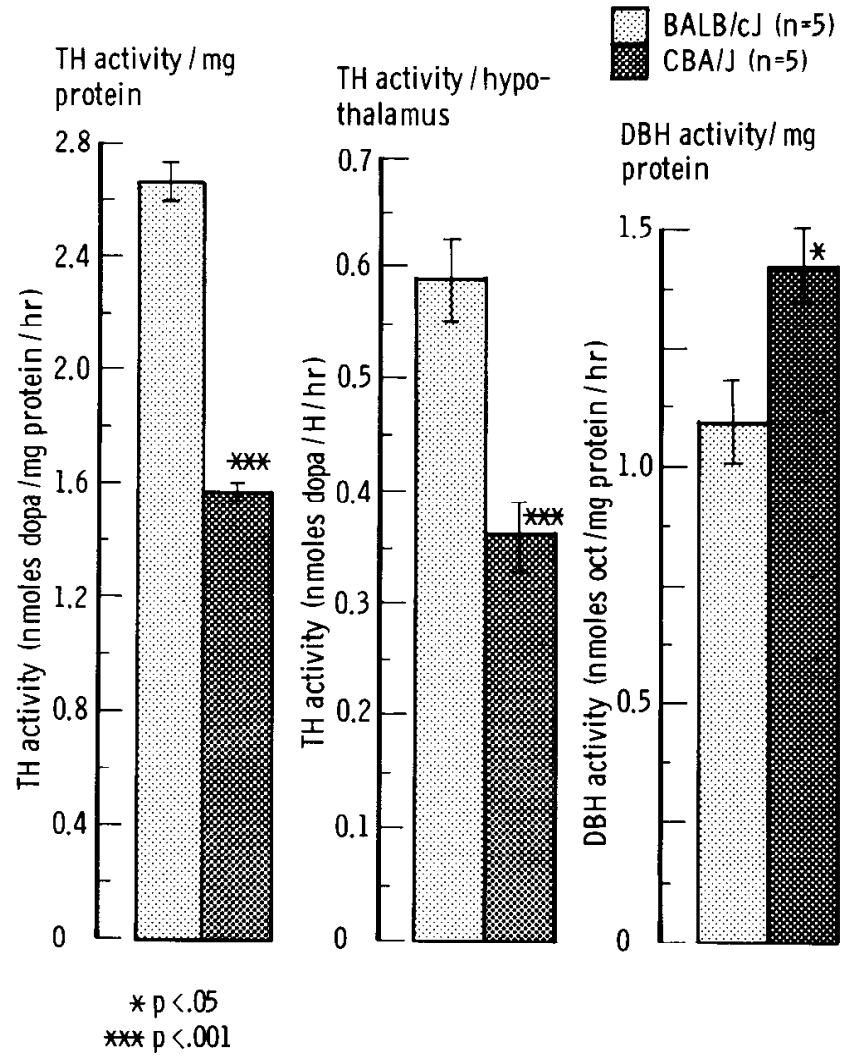

Figure 4. TH activity in whole hypothalamus is greater in $\mathrm{BALB} / \mathrm{cJ}$ mice than in $\mathrm{CBA} / \mathrm{J}$ mice, whether expressed per milligram of protein (left) or per hypothalamus (middle). $\mathrm{DBH}$ activity is greater in $\mathrm{CBA} / \mathrm{J}$ mice than in $\mathrm{BALB} / \mathrm{cJ}$ mice (right).
TABLE I

Strain differences in tyrosine hydroxylase activity and number of neurons in the hypothalamus and preoptic region

\begin{tabular}{|c|c|c|c|}
\hline & $\mathrm{BALB} / \mathrm{cJ}$ & $\mathrm{CBA} / \mathrm{J}$ & CBA/BALB \\
\hline \multicolumn{4}{|l|}{ Hypothalamus (HYP) } \\
\hline $\begin{array}{l}\text { a. } \mathrm{TH} \text { activity/mg } \\
\text { protein }^{\prime \prime}\end{array}$ & $2.67 \pm 0.07$ & $1.58 \pm 0.02^{b}$ & 0.59 \\
\hline $\begin{array}{l}\text { b. TH activity/ } \\
\text { HYP }\end{array}$ & $0.590 \pm 0.035$ & $0.365 \pm 0.025^{b}$ & 0.62 \\
\hline $\begin{array}{l}\text { c. Number of neu- } \\
\text { rons }\end{array}$ & $6607 \pm \mathbf{4 0 0}$ & $4451 \pm 313^{c}$ & 0.67 \\
\hline $\begin{array}{l}\text { d. 'TH activity/neu- } \\
\text { ron }\left(\times 10^{4}\right)\end{array}$ & 1.785 & 1.640 & 0.92 \\
\hline \multicolumn{4}{|l|}{ Preoptic region (POR) } \\
\hline $\begin{array}{l}\text { a. TH activity/mg } \\
\text { protein }\end{array}$ & $1.10 \pm 0.04$ & $0.683 \pm 0.032^{b}$ & 0.62 \\
\hline $\begin{array}{l}\text { b. TH activity/ } \\
\text { POR }^{d}\end{array}$ & $0.189 \pm 0.015$ & $0.104 \pm 0.008^{b}$ & 0.55 \\
\hline $\begin{array}{l}\text { c. Number of neu- } \\
\text { rons }\end{array}$ & $3949 \pm 338$ & $1929 \pm 175$ & 0.49 \\
\hline $\begin{array}{l}\text { d. TH activity/neu- } \\
\text { ron }\left(\times 10^{4}\right)\end{array}$ & 0.479 & 0.539 & 1.12 \\
\hline
\end{tabular}

${ }^{a} \mathrm{TH}$ activity expressed as $\mu \mathrm{mol}$ of DOPA/ $\mathrm{mg}$ of protein $/ \mathrm{hr}$.

${ }^{b} p<0.001, n=5$ to 8 for all groups.

${ }^{c} p<0.002 ; n=5$ to 8 for all groups.

${ }^{d} \mathrm{TH}$ activity expressed as $\mu \mathrm{mol}$ of DOPA $/$ region $/ \mathrm{hr}$.

mice than in CBA/J mice (Fig. 4). This finding indicated that the greater $\mathrm{TH}$ activity in BALB/cJ mice resulted from differences in dopaminergic, and not adrenergic, systems.

In a corresponding block of hypothalamus, we next counted the number of neurons stained with antibodies to $\mathrm{TH}$. In this brain region, BALB/cJ mice had significantly greater numbers of stained neurons than did CBA/ $\mathrm{J}$ mice (Table I). To determine if strain differences in number of DA neurons were equally distributed throughout the hypothalamus, the mean number of neurons at equivalent levels in the rostral-caudal axis of the hypothalamus was determined for each strain. Although $\mathrm{BALB} / \mathrm{cJ}$ mice had more neurons than did $\mathrm{CBA} / \mathrm{J}$ mice at all hypothalamic levels, significant strain differences were found only in mid-hypothalamus (Fig. 5A).

When TH activity was expressed per neuron, the amount of TH did not differ between the two strains (Table I). Thus, strain differences in TH activity in the hypothalamus, as in the substantia nigra, could be attributed to differences in the number of neurons containing the enzyme.

TH activity and neuron number in the preoptic region. In the preoptic region, $\mathrm{TH}$ activity, expressed both per milligram of protein and per region, was $60 \%$ less in $\mathrm{CBA} / \mathrm{J}$ mice than in BALB/cJ mice (Table I). The number of neurons stained with antibodies to $\mathrm{TH}$ was determined in the same region. $\mathrm{CBA} / \mathrm{J}$ mice had fewer DA neurons than BALB/cJ mice (Table I). The large strain differences in the number of neurons in the region just ventral to the anterior commissure are illustrated in Figure 6. As in the hypothalamus, BALB/cJ mice had more neurons than did $\mathrm{CBA} / \mathrm{J}$ mice throughout the rostral-caudal extent of the preoptic region, but significant differences were observed primarily in the middle of the nucleus, as illustrated in Figure $5 B$. When TH activ- 


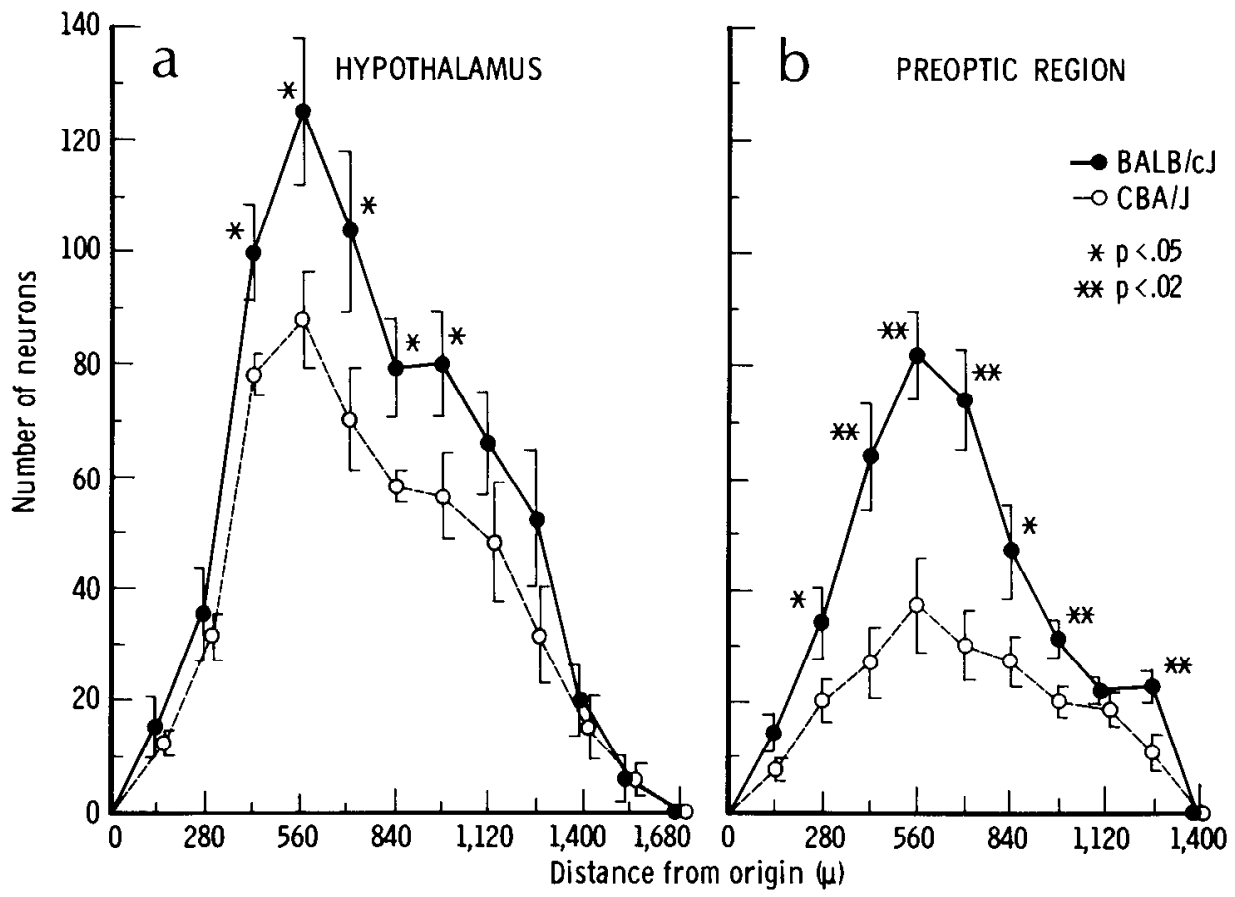

Figure 5. The number of TH-stained neurons was greater in BALB/cJ than in CBA/J mice along the entire rostral-caudal extent of both the hypothalamus $(a)$ and preoptic regions $(b)$. The origin represents that area where stained neurons first appeared. In the hypothalamus, arcuate and/or A13 neurons were first recognized in the retrochiasmatic region. In the preoptic area, stained neurons first appeared at the most rostral extension of the third ventricle.

ity was expressed per neuron, no differences between strains were observed, indicating that the strain differences in TH activity were attributable to differences in the number of dopamine neurons (Table I).

Medial and dorsal hypothalamus. TH activity was determined in the medial and dorsal hypothalamus, comprising the neurons of the zona incerta (A13) and dorsal periventricular neurons (A14), including the neurons lying within the dorsomedial nucleus of the hypothalamus. BALB/cJ mice had greater $\mathrm{TH}$ activity than did CBA/J mice (Table II).

Strain differences in the number of stained neurons in the same brain region were also determined. Again, there were more neurons in $\mathrm{BALB} / \mathrm{cJ}$ mice than in $\mathrm{CBA} / \mathrm{J}$ mice (Table II). The staining differences were most prominent in the dorsomedial and periventricular nuclei (Fig. 8), located ventral to the TH neurons of the zona incerta (Fig. 7), where strain differences were less striking. The differences in both $\mathrm{TH}$ activity and number of neurons were equivalent in magnitude, i.e., TH activity expressed per neuron was the same in both strains (Table II), suggesting that strain differences in $\mathrm{TH}$ activity were attributable to differences in the number of DA neurons.

Mediobasal hypothalamus. In a block of tissue dissected from the ventral portion of the hypothalamus, including the arcuate nucleus and the median eminence, TH activity was greater in BALB/cJ than in CBA/J mice (Table II). The strain differences in TH activity in the mediobasal hypothalamus were similar to those measured elsewhere (CBA/J was $51 \%$ of $\mathrm{BALB} / \mathrm{cJ})$. There were also strain differences in the number of neurons, with more neurons in the arcuate region of $\mathrm{BALB} / \mathrm{cJ}$ than in $\mathrm{CBA} / \mathrm{J}$ mice, as illustrated in Figure 9.
However, TH activity expressed per neuron was not the same in the two strains, with more TH activity per neuron in BALB/cJ than in CBA/J mice. Thus, differences in $\mathrm{TH}$ activity of the mediobasal hypothalamus were greater than those for neuron number.

\section{Discussion}

In 1970, Ciaranello et al. first discovered that the activity of TH varied in the whole brain between several inbred strains of mice. In their survey, they found that brains of BALB/cJ mice had twice as much TH activity as those of the CBA/J strain. Subsequent biochemical and immunocytochemical studies from our laboratory established that differences in TH activity in these two strains were detectable in microdissected areas containing cell bodies or terminals of midbrain DA systems (Ross et al., 1976; Baker et al., 1980b; Reis et al., 1982), but not in those of regions containing noradrenergic cell bodies. Moreover, the differences in TH activity reflected variations in the amount of $\mathrm{TH}$ enzyme protein (Ross et al., 1976). By careful morphometric analysis in which the number of neurons containing $\mathrm{TH}$ were counted, we demonstrated that differences in the amount and activity of TH were entirely attributable to differences in the number of midbrain neurons containing the enzyme (Ross et al., 1976; Baker et al., 1980b), all of which are dopaminergic. Indeed, when the TH activity of the entire midbrain for each strain was divided by the total number of stained perikarya, enzyme activity per neuron was approximalely equal between strains.

In the present study, we sought to determine whether the strain-linked differences in the number of DA neurons and, consequently, TH activity were generalized to 

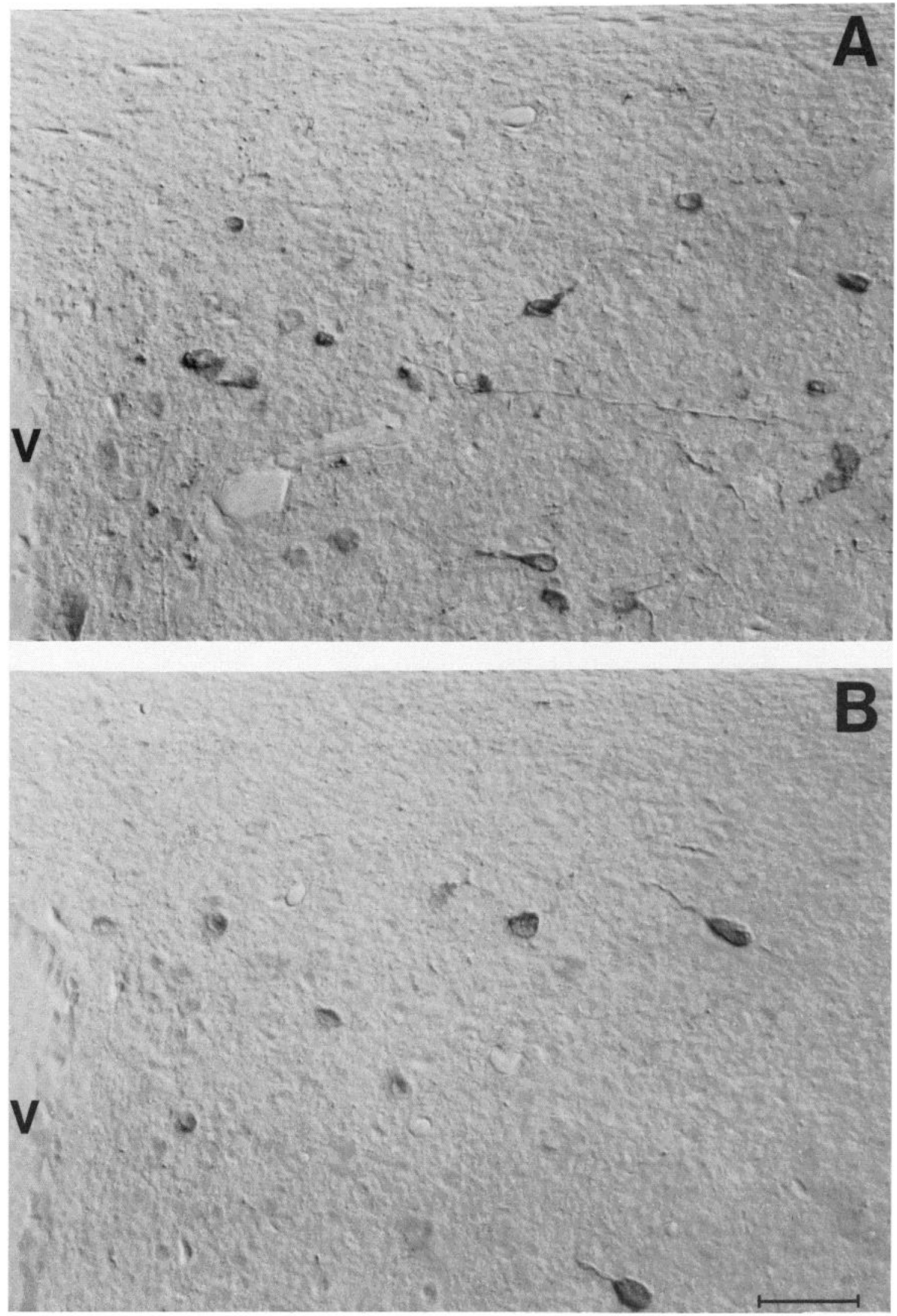

Figure 6. The number of stained neurons is greater in the preoptic region of the BALB/cJ strain $(A)$ than in the CBA/J strain $(B)$. The neurons in this region are small (less than $12 \mu \mathrm{m}$ in diameter) and round. $V$, third ventricle. Bar $=40 \mu \mathrm{m}$. 
TABLE II

Regional strain differences in tyrosine hydroxylase activity and number of neurons in the hypothalamus

$\mathrm{BALB} / \mathrm{cJ} \quad \mathrm{CBA} / \mathrm{J} \quad \mathrm{CBA} / \mathrm{BALB}$

\begin{tabular}{|c|c|c|c|}
\hline \multicolumn{4}{|l|}{$\begin{array}{l}\text { Medial and dorsal hy- } \\
\text { pothalamus } \\
\text { (MDH) }\end{array}$} \\
\hline $\begin{array}{l}\text { a. TH activity/mg } \\
\text { protein }\end{array}$ & $1.37 \pm 0.03$ & $0.97 \pm 0.03^{b}$ & 0.71 \\
\hline $\begin{array}{l}\text { b. TH activity/ } \\
\mathrm{MDH}^{\mathrm{c}}\end{array}$ & $0.470 \pm 0.021$ & $0.307 \pm 0.014^{b}$ & 0.65 \\
\hline $\begin{array}{l}\text { c. Number of neu- } \\
\text { rons }\end{array}$ & $3257 \pm 237$ & $2008 \pm 141$ & 0.62 \\
\hline $\begin{array}{l}\text { d. TH activity/neu- } \\
\text { ron }\left(\times 10^{4}\right)\end{array}$ & 1.443 & 1.528 & 1.06 \\
\hline \multicolumn{4}{|l|}{$\begin{array}{c}\text { Mediobasal hypothal- } \\
\text { amus (MBH) }\end{array}$} \\
\hline $\begin{array}{l}\text { a. } \mathrm{TH} \text { activity/mg } \\
\text { protein }^{\prime \prime}\end{array}$ & $2.54 \pm 0.12$ & $1.22 \pm 0.07^{b}$ & 0.48 \\
\hline b. TH activity/ & $0.274 \pm 0.01$ & $0.14 \pm 0.01^{b}$ & 0.51 \\
\hline $\begin{array}{l}\text { c. Number of neu- } \\
\text { rons }\end{array}$ & $3621 \pm 265$ & $2695 \pm 151^{d}$ & 0.74 \\
\hline $\begin{array}{l}\text { d. TH activity/neu- } \\
\text { ron }\left(\times 10^{4}\right)\end{array}$ & 0.757 & 0.523 & 0.69 \\
\hline
\end{tabular}

${ }^{a} \mathrm{TH}$ activity expressed as $\mu \mathrm{mol}$ of DOPA $/ \mathrm{mg}$ of protein $/ \mathrm{hr}$.

${ }^{b} p<0.001 ; n=5$ to 8 for all groups.

${ }^{c} \mathrm{TH}$ activity expressed as $\mu \mathrm{mol}$ of DOPA/region $/ \mathrm{hr}$.

${ }^{d} p<0.002 ; n=5$ to 8 for all groups.

DA systems other than those of midbrain, by examining DA cell groups of the hypothalamus.

By measuring $\mathrm{TH}$ activity regionally in different hypothalamic regions, we found that, as in midbrain, $\mathrm{TH}$ activity was always substantially less in CBA/J than in $\mathrm{BALB} / \mathrm{cJ}$ mice. Thus, in the whole hypothalamus, or regionally in the medial basal or dorsal hypothalamic areas and in the preoptic region, TH activity in $\mathrm{CBA} / \mathrm{J}$ mice was 50 to $60 \%$ of that of animals of the BALB/cJ strain. Within the hypothalamus, TH enzyme is contained not only in DA neurons but also in axonal projections of noradrenergic and adrenergic neurons whose cell bodies reside in the hindbrain (Moore and Bloom, 1979). However, it seems likely, for several reasons, that the differences in TH activity are due to variations of enzymes in the cell bodies and/or processes primarily of hypothalamic DA neurons.

First, bilateral lesions of the ventral noradrenergic bundle, which transect the ascending noradrenergic and presumably adrenergic innervation of the hypothalamus, do not reduce $\mathrm{TH}$ activity in the median eminence, arcuate nucleus, or ventromedial or dorsomedial hypothalamic nuclei (Kizer et al., 1976). At the same time, such lesions do reduce the activity of DBH up to $100 \%$ in the same nuclei. Since these lesions produce degeneration of the ascending noradrenergic and adrenergic fibers but do not affect the intrinsic dopaminergic neurons above the lesions, failure to alter TH activity in the hypothalamus indicates that the enzyme must arise from the intrinsic DA systems. Second, Demarest et al. (1979) found, in comparable studies, that hypothalamic TH activity, measured in vivo, was not significantly reduced by lesions produced by the intraventricular administration of 6-hydroxydopamine, a neurotoxin which destroys the hypothalamic noradrenergic, but not intrinsic dopaminergic, systems.

In view of the above, our finding that strain differences in hypothalamic TH activity are not paralleled by differences in DBH activity can be interpreted as reflecting variations of the enzyme in intrinsic dopaminergic systems and not noradrenergic and/or adrenergic innervation.

In contrast to other hypothalamic areas in which the ratios between TH activity and cell number were approximately equal (hence resulting in an enzyme to cell ratio of approximately 1 within each strain), in mediobasal hypothalamus the ratios differed. Thus, the ratio between $\mathrm{CBA} / \mathrm{J}$ and $\mathrm{BALB} / \mathrm{cJ}$ for $\mathrm{TH}$ activity was 0.51 , while for cell number it was 0.74 . In other words, there was less TH in the mediobasal area of CBA mice than was predicted on the basis of cell number alone.

The reason for the regional differences in the $\mathrm{TH}$ to cell number ratio between mediobasal hypothalamus and other hypothalamic regions is not clear. It might relate to the fact that the dissection of mediobasal hypothalamus contains not only the tuberoinfundibular neurons, but also their terminals in the median eminence which, because of proximity, could not be separately dissected for analysis. This is in contrast to the other hypothalamic regions in which many of the terminals, like those of midbrain neurons, lie at a distance from the perikarya (for review, see Moore and Bloom, 1978).

The relative concentrations of $\mathrm{TH}$ in the cell bodies and their terminals per unit of cytoplasm are unknown, largely because of difficulties in measuring the cytoplasmic volume of a particular class of terminals in a target area. In general, however, specific TH activity in most DA systems is lower in their terminal fields, presumably reflecting decreased packing density (Bacopoulos and Bhatnagar, 1977). The data (Kizer et al., 1974; Saavedra et al., 1974) suggest that $\mathrm{TH}$ activity in the arcuate nucleus containing the cell bodies of tuberoinfundibular neurons is similar to that of the median eminence, and raises the prospect of a high packing density in that terminal field. But even if terminal density in the median eminence is denser than that of other DA regions, the question still remains: how can strain differences be explained on that basis? One possibility is that the arborization of terminal fields differs between strains, independently of cell number. That terminal arborization may be controlled separately from cell bodies has been suggested by our studies on recombinant inbred mice, which revealed some elements of independent control over TH activity in the striatum, as compared to the cell body regions (Vadasz et al., 1982). Also, Levitt and Noebels (1981) demonstrated strain variations in the terminal field for noradrenergic systems which seemed to be independent of cell bodies.

A second explanation could relate to the fact that tuberoinfundibular DA neurons, in contrast to other DA neurons, lack both a high affinity DA uptake system (Demarest and Moore, 1979a) and presynaptic DA receptors (Demarest and Moore, 1979b). Also, dopamine is released directly (and not via a synapse) into the portal blood, and it is not metabolized to 3,4-dihydroxyphenylacetic acid (DOPAC) (Moore and Wuerthele, 1979). 

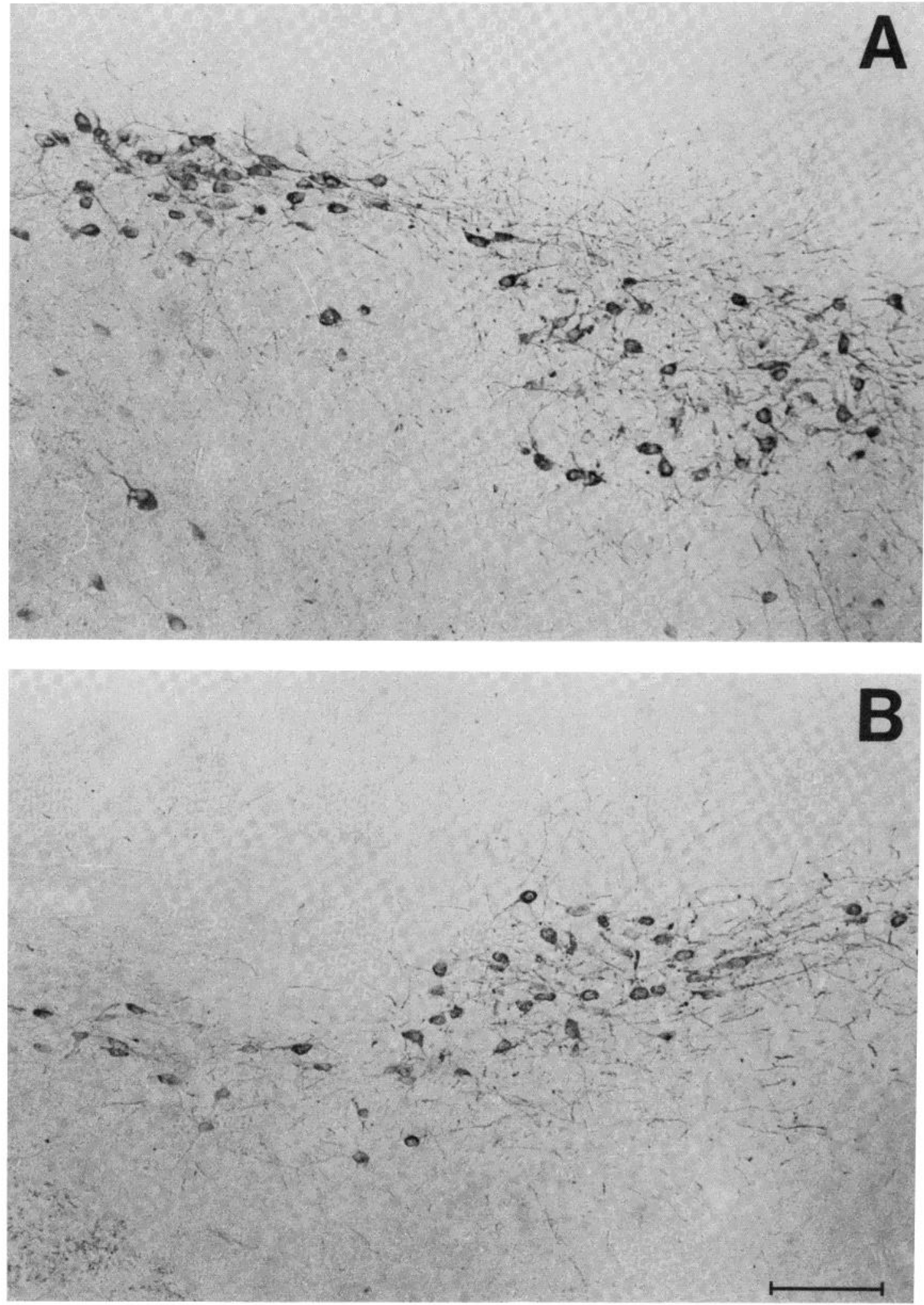

Figure 7. BALB/cJ mice $(A)$ have greater numbers of stained neurons in the zona incerta region than do CBA/J mice $(B)$. In both strains, the neurons are primarily medium-sized (15 to $20 \mu \mathrm{m}$ in diameter), and either stellate or fusiform. Note also the difference in configuration of the nucleus between strains, with more medially placed neurons in the BALB/cJ strain here resulting in part from a small difference in the rostral-caudal levels of the sections. Medial is to the right, with the median forebrain bundle on the lower left. Bar $=100 \mu \mathrm{m}$. 

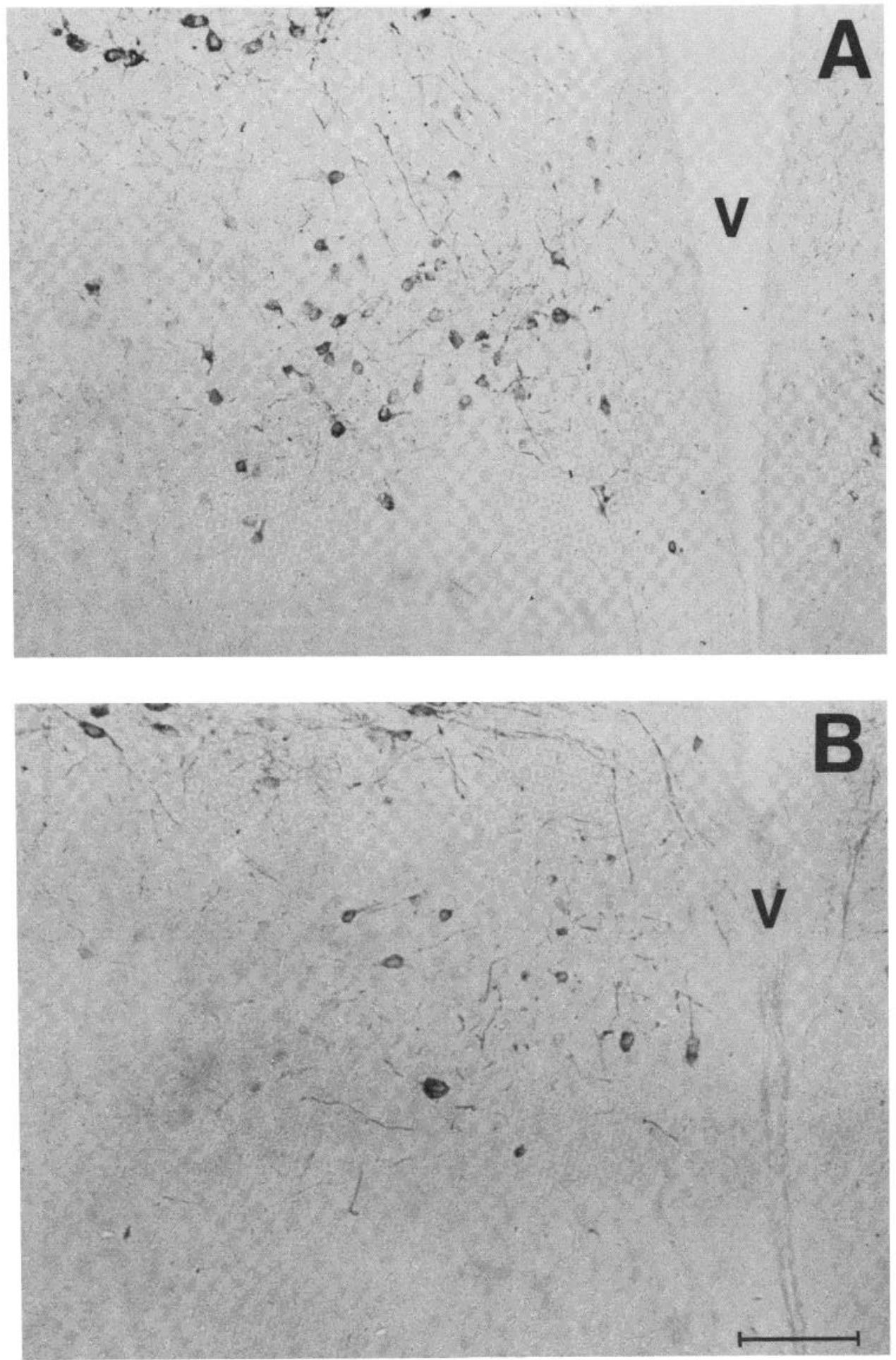

Figure 8. In the dorsal medial nucleus of the hypothalamus, BALB/cJ mice $(A)$ have $50 \%$ more stained neurons than do CBA/ $\mathrm{J}$ mice $(B)$. The neurons in the upper left are the zona incerta neurons illustrated in Figure $7 . V$, third ventricle. $B a r=100 \mu \mathrm{m}$.

Since there is no re-uptake into the terminal and no presynaptic receptors, feedback control of TH enzyme in these neurons differs from that in other DA systems (Moore and Wuerthele, 1979). In fact, DA release and, presumably, synthesis may be controlled by hormonal factors such as prolactin (Gudelsky, 1981).
Although the biochemical and behavioral sequelae of strain differences in $\mathrm{TH}$ activity and dopamine neuron number in the hypothalamus are unknown, it might be expected that differences in the regulation of prolactin secretion exist, since secretion of this hormone is so intimately linked to the functional state of the dopami- 

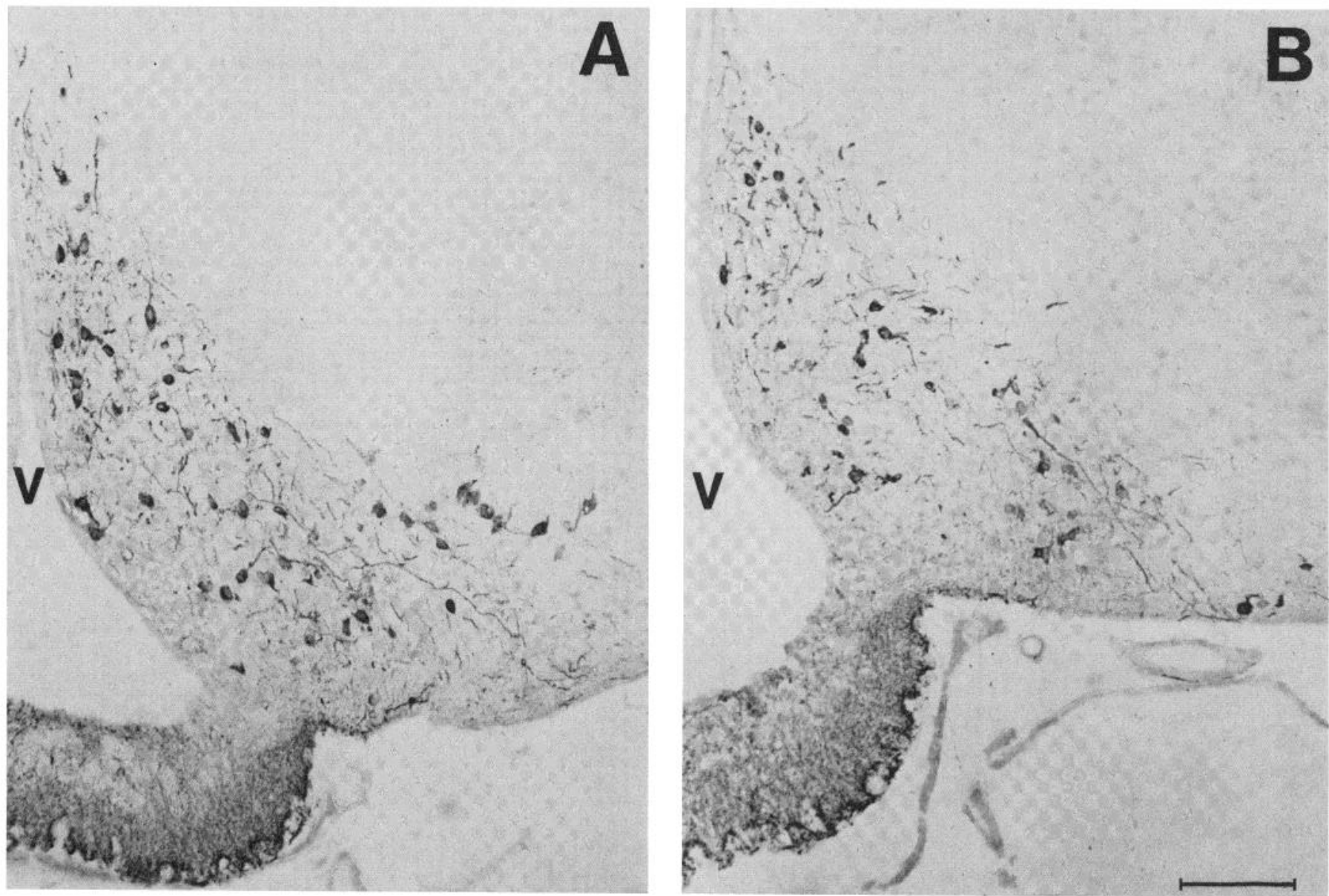

Figure 9. BALB/cJ mice $(A)$ have more stained neurons in the arcuate nucleus than do $\mathrm{CBA} / \mathrm{J}$ mice $(B)$. $V$, third ventricle. Bar $=100 \mu \mathrm{m}$.

nergic neuron (Gudelsky, 1981). The control of the secretion of other hypothalamic hormones, for example, growth hormone (Martin, 1980) or melanocyte-stimulating hormone (Kastin et al., 1980), might also be altered by extensive strain differences in the number of dopamine neurons, since DA mechanisms have been implicated in their release.

The underlying mechanism(s) accounting for strain differences in the number of DA neurons is not known. As previously discussed (Baker et al., 1980b), it is unlikely that there is a difference between strains in the antigenicity of the TH enzyme, since enzyme kinetics are the same in the two strains. It is possible that some neurons in the $\mathrm{CBA} / \mathrm{J}$ strains have insufficient $\mathrm{TH}$ enzyme to be biochemically or immunocytochemically demonstrable. This hypothesis would be difficult to prove and practically indistinguishable from the mechanism we favor: that $\mathrm{CBA} / \mathrm{J}$ mice have fewer DA neurons than do $\mathrm{BALB} / \mathrm{cJ}$ mice. Although similar mechanisms appear to account for the differences in adult TH activity in all brain regions, the possibility that they have different developmental etiologies still cannot be excluded.

In summary, we have demonstrated that in the hypothalamus, as in the substantia nigra, observed strain differences in $\mathrm{TH}$ activity are correlated with differences in the number of dopamine neurons stained with antibodies to TH. In these two mouse strains, the differences in TH activity can be demonstrated in all brain dopamine systems and can be attributed to strain differences in the number of demonstrable dopamine neurons.

\section{References}

Bacopoulos, N. G., and R. K. Bhatnagar (1977) Correlation between tyrosine hydroxylase activity and catecholamine concentration or turnover in brain regions. J. Neurochem. 29: 639-643.

Baker, H., T. H. Joh, and D. J. Reis (1980a) Genetic variations in number of dopamine neurons in hypothalamus and preoptic region of two inbred mouse strains. Soc. Neurosci. Abstr. 6: 742 .

Baker, H., T. H. Joh, and D. J. Reis (1980b) Genetic control of the number of midbrain dopaminergic neurons in inbred strains of mice: Relationship to size and neuronal density of the striatum. Proc. Natl. Acad. Sci. U. S. A. 77: 4369-4373.

Benno, R. H., L. W. Tucker, T. H. Joh, and D. J. Reis (1982) Quantitative immunocytochemistry of tyrosine hydroxylase in rat brain. II. Variations in the amount of tyrosine hydroxylase among individual neurons of the locus ceruleus in relationship to neuronal morphology and topography. Brain Res. 246: 237-247.

Björklund, A., and A. Nobin (1973) Fluorescence histochemical and microspectrofluorometric mapping of dopamine and noradrenaline cell groups in the rat diencephalon. Brain Res. 51: 193-205.

Ciaranello, R. D., R. Barchas, S. Kessler, and J. D. Barchas (1970) Catecholamines: Strain differences in biosynthetic en- 
zyme activity in mice. Life Sci. 2 (I): $565-572$.

Dahlström, A., and K. Fuxe (1964) Evidence for the existence of monoamine-containing neurons in the central nervous system. I. Demonstration of monoamines in the cell bodies of brain stem neurons. Acta Physiol. Scand. Suppl. 62(232): 155 .

Demarest, K. T., and K. E. Moore (1979a) Lack of a high affinity transport system for dopamine in the median eminence and posterior pituitary. Brain Res. 171: 545-581.

Demarest, K. T., and K. E. Moore (1979b) Comparison of dopamine synthesis regulation in the terminals of nigrostriatal, mesolimbic, tuberoinfundibular and tubcrohypophyseal neurons. J. Neural Transm. 46: 263-277.

Demarest, K. T., R. H. Alper, and K. E. Moore (1979) Dopa accumulation is a measure of dopamine synthesis in the median eminence and posterior pituitary. J. Neural Transm. 46: $183-193$.

Dornfeld, E. J., D. W. Slater, and H. Scheffe (1942) A method for accurate determination of volume and cell numbers in small organs. Anat. Rec. 82: 255-259.

Gudelsky, G. A. (1981) Tuberoinfundibular dopamine neurons and the regulation of prolactin secretion. Psychoneuroendocrinology 6: 3-16.

Hökfelt, T., O. Johannson, K. Fuxe, M. Goldstein, and D. Park (1976) Immunohistochemical studies on the localization and distribution of monoamine neuron systems in the rat brain. I. Tyrosine hydroxylase in the mes and diencephalon. Med. Biol. 54: 427-453.

Kastin, A. J., A. V. Schally, and R. M. Kostrzewa (1980) Possible aminergic mediations of MSH release and the CNS effects of MSH and MIF-I. Fed. Proc. 39: 2931-2936.

Kizer, J. S., M. Palkovits, J. Zivin, M. Brownstein, J. M. Saavedra, and I. J. Kopin (1974) The effect of endocrinological manipulations on tyrosine hydroxylase and dopamine$\beta$-hydroxylase activities in individual hypothalamic nuclei of the adult male rat. Endocrinology 95: 799-812.

Kizer, J. S., E. Muth, and D. M. Jacobowitz (1976) The effect of bilateral lesions of the ventral noradrenergic bundle on endocrine-induced changes of tyrosine hydroxylase in the rat median eminence. Endocrinology 98: 886-893.

Levitt, P., and J. L. Noebels (1981) Mutant mouse tottering: Selective increase of locus ceruleus axons in a defined singlelocus mutation. Proc. Natl. Acad. Sci. U. S. A. 78: 4630-4634.

Loo, Y. T. (1931) The forebrain of the opossum, Didelphis virginiana. J. Comp. Neurol. 52: 1-118.

Martin, J. B. (1981) Functions of central nervous neurotransmitters in regulation of growth hormone secretions. Fed. Proc. 39: 2902-2906.

Moore, K. E., and S. M. Wuerthele (1979) Regulation of nigro- striatal and tuberoinfundibular-hypophyseal dopaminergic neurons. Prog. Neurobiol. 13: 325-329.

Moore, R. Y., and F. E. Bloom (1978) Central catecholamine neuron systems: Anatomy and physiology of the dopamine system. Annu. Rev. Neurosci. 1: 129-169.

Moore, R. Y., and F. E. Bloom (1979) Central catecholamine neuron systems: Anatomy and physiology of the norepinephrine and epinephrine systems. Annu. Rev. Neurosci. 2: 113168.

Pickel, V. M., T. H. Joh, P. M. Field, C. G. Becker, and D. J. Reis (1975) Cellular localization of tyrosine hydroxylase by immunohistochemistry. J. Histochem. Cytochem. 23: 1-12.

Reis, D. J., and P. B. Molinoff (1972) Brain dopamine- $\beta$-hydroxylase: Regional distribution and effects of lesions and 6hydroxydopamine on activity. J. Neurochem. 19: 195-204.

Reis, D. J., T. H. Joh, and R. A. Ross (1975) Effects of reserpine on activities and amounts of tyrosine hydroxylase and dopamine- $\beta$-hydroxylase in catecholaminergic neuronal systems in rat brain. J. Pharmacol. Exp. Ther. 193: 775-784.

Reis, D. J., J. S. Fink, and H. Baker (1982) A genetic control of number of dopamine neurons in brain: Relationship to behavior and responses to psychoactive drugs. In Genetics of Neurological and Psychiatric Disorders, S. S. Kety, L. P. Rowland, R. L. Sidman, and S. W. Matthysse, eds., pp. 5575, Raven Press, New York.

Ross, R. A., A. B. Judd, V. M. Pickel, T. H. Joh, and D. J. Reis (1976) Strain-dependent variations in number of mid-brain dopaminergic neurons. Nature 264: 654-656.

Saavedra, J. M., M. Brownstein, M. Palkovits, S. Kiser, and J. Axelrod (1974) Tyrosine hydroxylase and dopamine- $\beta$-hydroxylase: Distribution in the individual rat hypothalamic nuclei. J. Neurochem. 23: 869 871.

Sternberger, L. A., P. H. Hardy, Jr., J. J. Cuculus, and H. G. Meyer (1970) The unlabeled antibody enzyme method of immunohistochemistry: Preparation and properties of soluble antigen-antibody complex (horseradish peroxidase-antihorseradish peroxidase) and its use in identification of spirochites. J. Histochem. Cytochem. 18: 315-333.

Teitelman, G., H. Baker, T. H. Joh, and D. J. Reis (1979) Appearance of catecholamine-synthesizing enzymes during development of rat sympathetic nervous system: Possible role of environment. Proc. Natl. Acad. Sci. U. S. A. 76: 509513.

Vadasz, C., H. Baker, T. H. Joh, A. Lajtha, and D. J. Reis (1982) The inheritance and genetic correlation of tyrosine hydroxylase activities in the substantia nigra and corpus striatum in the CXB recombinant inbred mouse strains. Brain Res. 234: 1-9. 